\title{
Clinical \\ pharmacokinetics of clarithromycin
}

\author{
MARC LeBEL, PhARMD, FCCP
}

$\mathrm{C}$ LARITHROMYCIN IS A NEW 14-MEMBERED MACROLIDE ANTImicrobial agent that exhibits a broad spectrum of antimicrobial activity against Gram-positive and Gramnegative aerobes. Susceptible pathogens include staphylococci, streptococci, Haemophilus influenzae, Legionella pneumophila, Mycobacterium, Chlamydia and Mycoplasma species (1). In addition, the 14-hydroxy metabolite of clarithromycin appears to have antimicrobial activity which may be additive or synergistic to that of the parent compound (2).

Clarithromycin is an acid-stable analogue of erythromycin with a methoxy substitution at C- 6 of the erythronolide ring. This structural alteration prevents acid-induced conversion of the molecule to inactive spiroketal forms in the stomach, improves bioavailability and gastrointestinal tolerance after an oral dose, and therefore increases antibacterial activity (3) compared with erythromycin.

\section{ABSORPTION}

Clarithromycin exhibits a more predictable pattern of absorption than the prototype. After a single oral dose of a $250 \mathrm{mg}$ tablet, clarithromycin is rapidly absorbed, with a mean time to maximum concentration ( $\left.\mathrm{T}_{\max }\right)$ of approximately $2 \mathrm{~h}$ and mean maximum con-
}

centration $\left(\mathrm{C}_{\max }\right)$ of $0.76 \mu \mathrm{g} / \mathrm{mL}(3)$. Steady-state peak serum concentrations are 1.0 to $1.5 \mu \mathrm{g} / \mathrm{mL}$ after a $250 \mathrm{mg}$ twice daily dose and 2.0 to $3.0 \mu \mathrm{g} / \mathrm{mL}$ after a $500 \mathrm{mg}$ twice daily dose. In a study looking at the influence of increasing clarithromycin dose, the mean $\mathrm{C}_{\max }$ increased approximately in proportion to dose from $0.35 \mu \mathrm{g} / \mathrm{mL}$ (100 mg dose) to $3.97 \mu \mathrm{g} / \mathrm{mL}$ (1200 mg dose) (4). Other clarithromycin pharmacokinetic parameters exhibited nonlinearity (see below). When clarithromycin was administered as a suspension ( $7.5 \mathrm{mg} / \mathrm{kg}$ body weight) to 24 infants and children, mean $\mathrm{C}_{\max }$ values reached $3.59 \mu \mathrm{g} / \mathrm{mL}$ (5).

The presence of food in the stomach causes a slight delay in both the onset of absorption of the parent compound and the formation of the 14-hydroxy metabolite; overall bioavailability is increased in the presence of food (6). Unlike erythromycin, clarithromycin is stable in gastric acid.

In order to assess the absolute bioavailability of clarithromycin, 19 healthy subjects received - in a three-way, randomized, crossover design trial - two oral formulations $(250 \mathrm{mg})$ and intravenous clarithromycin lactobionate $(250 \mathrm{mg})$ (3). The clarithromycin $\mathrm{AUC}_{0}-24$ ratio of oral versus intravenous was 0.51 , indicative of a $51 \%$ bioavailability of parent compound. However,

\footnotetext{
Laboratoire de Pharmacocinétique Clinique, Université Laval, École de pharmacie, Cité Universitaire, Buébec, Québec

Correspondence: Dr Marc LeBel, Professor and Director, Laboratoire de Pharmacocinétique Clinique, Université Laval, École de pharmacie, Cité Universitaire, Pavillon Ferdinand-Vandry. Québec G1K 7P4. Telephone (418) 656-3158, Fax (418) 656-2305
} 
when adjusted for potency (oral: $98.4 \%$, iv: $106.6 \%$ ) the absolute bioavailability of the parent compound was $55 \%$. The AUC for the metabolite was higher with oral dosing, suggesting that a substantial amount of 14-hydroxy clarithromycin is metabolized on first pass through the liver. Oral bioavailability of clarithromycin does not appear to be dose dependent on the basis of urinary excretion data.

\section{DISTRIBUTION AND TISSUE PENETRATION}

Macrolide antibiotics are known to bind to plasma proteins, particularly alpha ${ }_{1}$-acid glycoprotein. These compounds are lipophilic and they penetrate well into tissues (7). Clarithromycin penetrates particularly well throughout the body while maintaining high concomitant serum concentrations.

Penetration into suction-induced blister fluids was determined in healthy volunteers following three days of clarithromycin $250 \mathrm{mg}$ twice a day (8). Clarithromycin and its 14-hydroxy metabolite yielded percentage of penetration (using AUC ratios) of 55 and $75 \%$, respectively. In a preliminary study, clarithromycin $(250 \mathrm{mg}$ single dose) attained saliva to plasma and tears to plasma ratios of 1.73 and 1.01 , respectively (9).

Scaglione and Fraschini (10) evaluated the diffusion of clarithromycin into respiratory tissues, including the nasal mucosa, tonsils and lungs in adult patients undergoing surgery. For the three days preceding their surgical procedures, patients received clarithromycin, $250 \mathrm{mg}$ twice daily (nasal mucosa or tonsillar tissue), or $500 \mathrm{mg}$ twice daily (lung parenchyma). For clarithromycin and its active metabolite, half-lives $(\mathrm{tl} / 2 \beta)$ in sputum were 1.3- to 1.6-fold longer than those in serum. In tonsils, mean $4 \mathrm{~h}$ post dose parent and metabolite concentrations were 5.3 and $3.1 \mathrm{mg} / \mathrm{kg}$, respectively, and mean $12 \mathrm{~h}$ post dose values were 2.1 and 1.2 $\mathrm{mg} / \mathrm{kg}$, respectively. Parent and metabolite concentrations in nasal mucosa $4 \mathrm{~h}$ post dose were 5.9 and 3.2 $\mathrm{mg} / \mathrm{kg}$, respectively, and mean $12 \mathrm{~h}$ post dose values were 2.2 and $1.5 \mathrm{mg} / \mathrm{kg}$, respectively. In lung tissue, parent and metabolite concentrations $4 \mathrm{~h}$ post dose were 13.5 and $7.2 \mathrm{mg} / \mathrm{kg}$, respectively, and $12 \mathrm{~h}$ post dose values were 2.8 and $2.0 \mathrm{mg} / \mathrm{kg}$, respectively.

Although intraphagocytic bioactivity is not a common property of antimicrobial agents (11), the newer macrolide antibiotics achieve high intracellular concentrations. Clarithromycin has been shown to penetrate macrophages and leukocytes, which makes it particularly effective against intracellular pathogens such as $L$ pneumophila and Chlamydia species (1). In contrast, penicillin and cephalosporin antibiotics are not actively concentrated by phagocytes, and they possess only modest, if any, intracellular activity (11).

Anderson and colleagues (11) observed that erythromycin was rapidly concentrated by neutrophils, with an intracellular to extracellular (I/E) ratio of $7: 3$. The $\mathrm{I} / \mathrm{E}$ ratio for clarithromycin was found to be $9: 1$. These investigators concluded that the superior pharmacokinetic properties of clarithromycin will lead to increased intraphagocytic accumulation and bioactivity in vivo.

Therapeutic concentrations of clarithromycin have also been found to stimulate protein kinase $\mathrm{C}$ activity in polymorphonuclear leukocytes. Thus, in addition to its antimicrobial activity, the drug stimulates cellular host defence mechanisms involving the activation of protein kinase C (12).

\section{METABOLISM AND ELIMINATION}

Although the metabolism of the macrolide antibiotics has not been extensively studied, it is known that a portion of the dose is metabolized in the liver. Macrolide antibiotics are demethylated by the cytochrome P-450-III microsomal enzyme system. Clarithromycin is metabolized to eight metabolites, but only one - the 14-hydroxy metabolite - has been shown to have antibacterial activity. Minor metabolic pathways are N-demethylation and hydrolysis of the cladinose sugar to produce inactive metabolites (13). The pharmacologically active 14hydroxy metabolite appears to undergo further metabolism (N-demethylation or hydrolysis of the cladinose sugar) to inactive secondary metabolites.

The pharmacokinetics of clarithromycin appear to be nonlinear, apparently as a result of capacity-limited saturation of metabolic pathways. However, such nonlinearity is slight at the recommended doses. Disproportionate increases in total clearance, terminal disposition half-life and dose-normalized area under the plasma concentration-versus-time curve have been reported in patients receiving a single high dose (1.2 g) or multiple doses. Similar dose dependency has been observed with the 14-hydroxy metabolite (4). With increasing dose, a significant decline in the metabolite/parent compound plasma concentration ratio and a significant decline in urinary recovery of the metabolite were observed; this is consistent with a capacitylimited metabolism of the parent compound to the 14-hydroxy metabolite. Similar nonlinear pharmacokinetics have been noted with erythromycin (14).

Thirty to $40 \%$ of an oral dose of clarithromycin is excreted unchanged or as an active metabolite via the kidneys, and the remainder is excreted via the bile (15). In individuals with normal renal function, the half-lives of clarithromycin and its 14-hydroxy metabolite after a $500 \mathrm{mg}$ dose are 5 and $7 \mathrm{~h}$, respectively (16). As renal function declines, the serum half-lives of these compounds increase to 7.7 and $14 \mathrm{~h}$, respectively. At a creatinine clearance of 30 to $80 \mathrm{~mL} / \mathrm{min}$, clarithromycin's half-life is $12 \mathrm{~h}$; this interval increases to $32 \mathrm{~h}$ when the creatinine clearance falls below $30 \mathrm{~mL} / \mathrm{min}$. For 14-hydroxy clarithromycin at the lower creatinine clearance the half-life is $47 \mathrm{~h}$. Clearly, an alteration in the dose regimen would be advisable in patients with severely impaired renal function.

Severe hepatic impairment could theoretically alter 
the pharmacokinetics of clarithromycin and its metabolite so that less metabolite would be formed, and renal clearance of the parent compound would increase. Steady-state levels of unchanged clarithromycin in hepatically impaired patients are similar to those in normal subjects, so if renal function is normal, the drug can be administered without dose adjustment (17).

\section{DOSAGE REGIMENS}

The usual adult dosage of clarithromycin for infections of the respiratory tract, skin and soft tissues is 250 to $500 \mathrm{mg}$ every $12 \mathrm{~h}$ for seven to 14 days. In patients with both hepatic and renal impairment, or in the presence of severe renal impairment, a decreased dose or prolonged dosing intervals may be appropriate (17). In infants and children, $7.5 \mathrm{mg} / \mathrm{kg}$ body weight bid seems appropriate (5). (In Canada, clarithromycin is currently indicated for adults and children above 12 years of age.)

\section{REFERENCES}

1. Hardy DJ, Hensey DM, Beyer UM, et al. Clarithromycin: A unique macrolide. A pharmacokinetic, microbiological, and clinical overview. Diag Microbiol Infect Dis 1991;14:1-15.

2. Hardy D, Swanson RN, Rode RA, Marsh K. Shipkowitz NL, Clement JJ. Enhancement of the in vitro and in vivo activities of clarithromycin against Haemophilus influenzae by 14-hydroxy-clarithromycin, its major metabolite in humans. Antimicrob Agents Chemother 1990;34:1407-13.

3. Chu S-Y, Deaton R, Cavanaugh J. Absolute bioavailability of clarithromycin after oral administration in humans. Antimicrob Agents Chemother 1992;36:1147-50.

4. Chu S-Y, Sennello LT, Bunnell ST, et al. Pharmacokinetics of clarithromycin, a new macrolide, after single ascending oral doses. Antimicrob Agents Chemother 1992;36:2447-53.

5. Gan VN, Chu S-Y, Kusmiesz HT, et al. Pharmacokinetics of a clarithromycin suspension in infants and children. Antimicrob Agents Chemother 1992;36:2478-80.

6. Chu S-Y, Park T. Drug-food interaction potential of clarithromycin: A new macrolide antimicrobial. J Clin Pharmacol 1992;32:32-6.

7. Bahal N, Nahata M. The new macrolide antibiotics: Azithromycin, clarithromycin, dirithromycin, and roxithromycin. Ann Pharmacother 1992:26:46-55.

8. Walstad RA, Thurmann-Nielson E, Hellum KB. The pharmacokinetics and penetration of clarithromycin and its 14-hydroxy metabolite into suction skin blisters. The 17th International Congress of Chemotherapy, Berlin, 1991.

9. Sörgel F, Naber KG, Muth P, et al. The penetration of clarithromycin into body fluids in man. The 1st International Conference on the Macrolides, Azalides and Streptogramins. Santa Fe, 1992.

10. Scaglione F, Fraschini F. Distribution of clarithromycin and its metabolite (14-OH) in therapeutically relevant respiratory tract tissues and fluids. The First International Conference on the Macrolides, Azalides, and Streptogramins. Santa Fe, 1992.

11. Anderson R, Joone G, van Rensburg EJ. An in-vitro evaluation of the cellular uptake and intraphagocytic bioactivity of clarithromycin (A-56268, TE-031), a new macrolide antimicrobial agent. J Antimicrob Chemother 1988;22:923-33.

12. Pfleger S, Makristathis A, Block LH, et al. Clarithromycin stimulates intracellular killing of $S$ aureus 502 and respiratory burst of polymorpho- nuclear leukocytes via activation of protein kinase C. 17th International Congress of Chemotherapy, Berlin, 1991:143.

13. Ferrero JL, Bopp BA, Marsh KC, et al. Metabolism and disposition of clarithromycin in man. Drug Metab Disp 1990; 18:441-6.

14. Josefsson K, Bergan T, Magni L. Dose-related pharmacokinetics after oral administration of a new formulation of erythromycin base. $\mathrm{Br} \mathrm{J}$ Clin Pharmacol 1982:13:685-91

15. Sturgill MG, Rapp RP. Clarithromycin: Review of a new macrolide antibiotic with improved microbiologic spectrum and favorable pharmacokinetic and adverse effect profiles. Ann Pharmacother 1992;26:1099-108.

16. Neu H. The development of macrolides: Clarithromycin in perspective. J Antimicrob Chemother 1991;27 (Suppl A):1-9.

17. Piscitelli SC, Danziger LH, Rodzold KD, et al. Clarithromycin and azithromycin: New macrolide antibiotics. Clin Pharmacy 1992;11:137-52. 


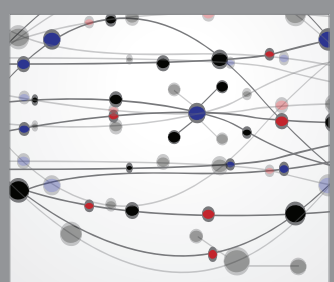

The Scientific World Journal
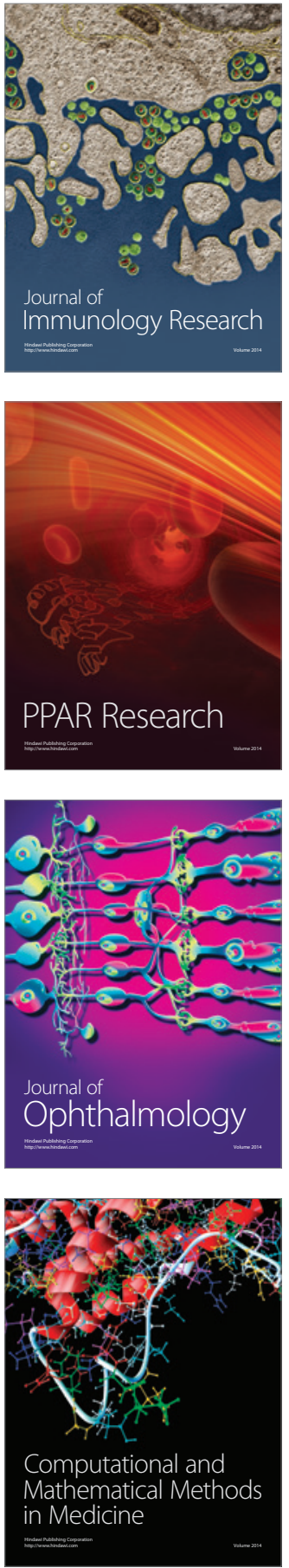

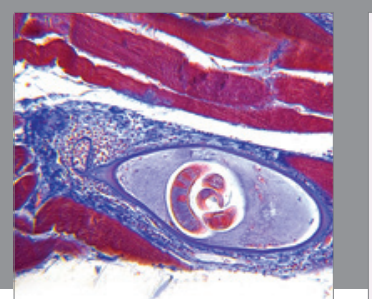

Gastroenterology Research and Practice

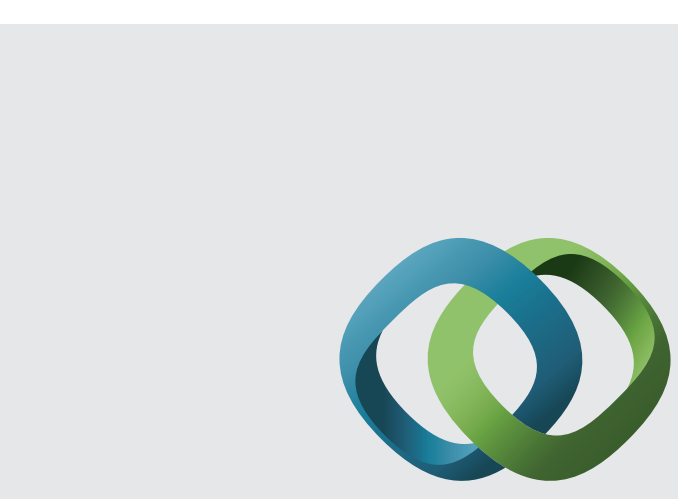

\section{Hindawi}

Submit your manuscripts at

http://www.hindawi.com
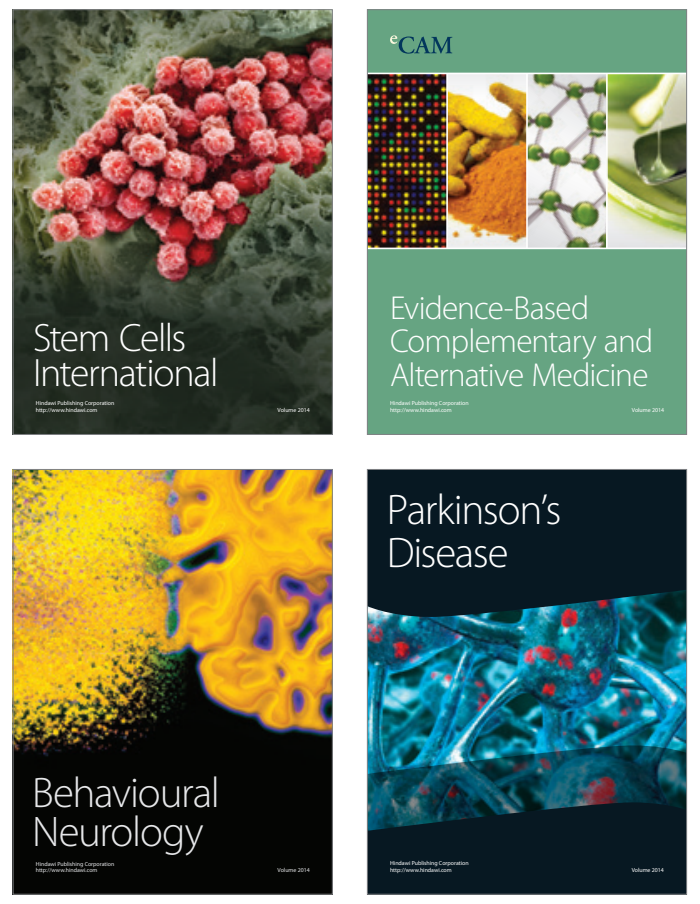
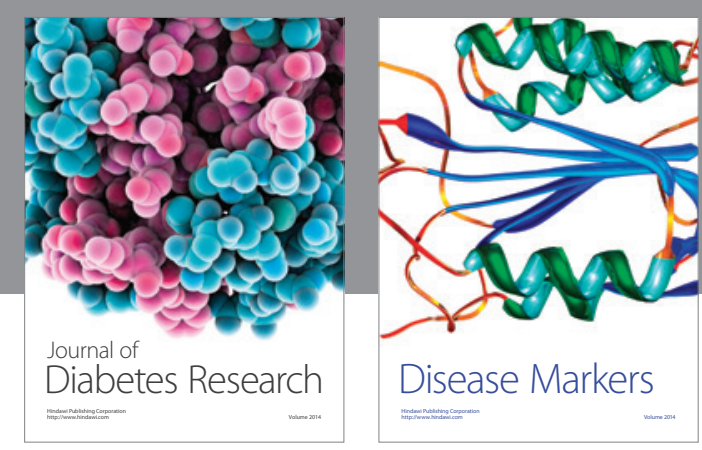

Disease Markers
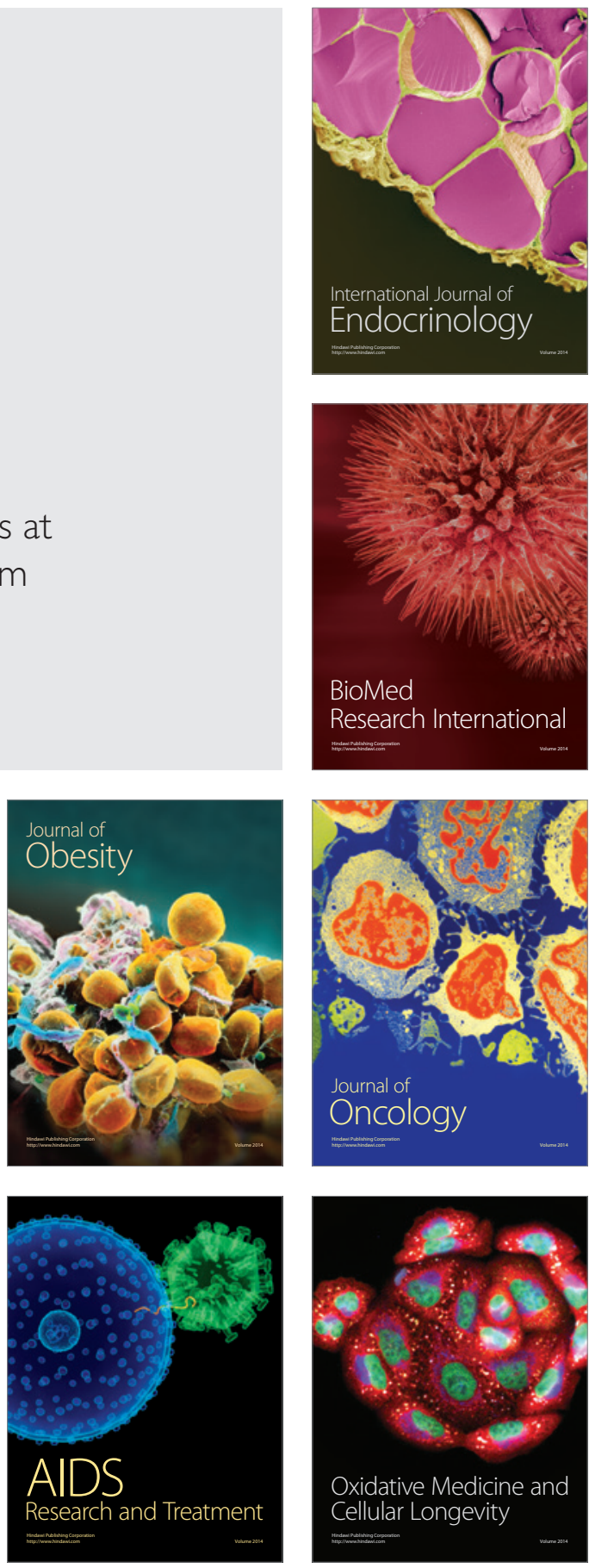